\title{
Stretched exponential as one of the alternatives for the power law to fit ranked species abundance data
}

\author{
$\checkmark$ Correspondence \\ ger- \\ ben.straatsma@gmail.com \\ 8 Disciplines \\ Ecology \\ Q Keywords \\ Species Abundance Distribu- \\ tion \\ Stretched Exponential \\ t. Type of Observation \\ Standalone \\ \& Type of Link \\ Resources / Big Data
}

(C) Submitted Nov 29, 2016 (-) Published Jan 26, 2017

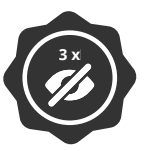

Triple Blind Peer Review The handling editor, the reviewers, and the authors are all blinded during the review process.

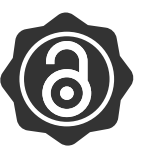

Full Open Access Supported by the Velux Foundation, the University of Zurich, and the EPFL School of Life Sciences.

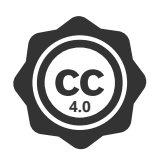

Creative Commons 4.0 This observation is distributed under the terms of the Creative Commons Attribution 4.0 International License.

\section{Gerben Straatsma, Simon Egli}

Aquatic Ecology and Water Quality Management Group, Wageningen University and Research Center; Forest Dynamics, Swiss Federal Research Institute WSL

\begin{abstract}
A central object in community ecology is species abundance distribution. We are interested in the power law and its allies for ranked species abundance data. We collected 12 large data sets consisting of many samples. The preliminary fitting result makes a robust impression (12 systems at three scales of integration) that the stretched exponential is an interesting alternative for the power law. For further work, advanced statistics are required. Not only 'our' data but, quite often, other data as well consist of sample $\times$ species cross-tables. With cross-tables, also 'within species over samples' characteristics can be studied. An integrated view on data patterns in multi-sample sets may help to identify generative processes for and the formulation of a relatively simple model for species abundance data.
\end{abstract}

\section{Objective}

The direct aim is to generate interest again in the power law, especially in its allies like the stretched exponential, for species abundance data. Further reaching aims, to be tackled in the future and for which we introduce a frame, are (i) to generate the interest of community ecologists in the generative processes of the power law and allies (that have been studied in other fields of science) and (ii) to complete the quest for a simple yet meaningful equation/model for the SAD.

\section{Introduction}

A central object in community ecology is species abundance distribution (SAD). It has been studied for over a century since Raunkiaer (in [1]). The review of an expert group [2] is a benchmark for properties and generative theory. The edited volume [3] on biological diversity is, among others, an update. For applications of the SAD, like the measurement of biodiversity, we refer to [4].

The expert group [2] described a law for species abundance data: "When plotted as a histogram of number (or percent) of species on the y-axis vs. abundance on an arithmetic x-axis, the classic hyperbolic, 'lazy J-curve' or 'hollow curve' is produced, indicating a few very abundant species and many rare species (Fig. 1a). In this form, the law appears to be universal; we know of no multispecies community, ranging from the marine benthos to the Amazonian rainforest, that violates it" (in our Supplement A, we make some remarks to the meaning of 'community' and 'sample'). Several terms are used for a 'hollow curve': the distribution is (right)-skewed, long-tailed, has extreme values, shows rare events. Is there a simple meaningful equation for 'the' species abundance distribution? One is inclined to think so if there is a 'universal law'. Review [2] is steeped with the idea of a relatively simple equation for SADs, but it presents the opposite too, that different communities have rather different SADs and that groups of species within a community have different SADs, making the community's SAD a mixed one [5]. The SAD is mostly treated as a histogram, based on the binning of data into frequency classes (for a probability mass or density function). However, the SAD can be illustrated as a rank abundance or Whittaker plot (see [2], their Fig. 1c; see also [6] [7]). Ranked data are used for exploratory data analysis. Rank-size plots and (cumulative) probability plots are strongly related [8] [9] (and see our Supplement B). SADs bear similarity to distributions in other fields of science [10] [11] [12].

Long-tailed distributions of natural and manmade phenomena, in rank-size form (where 'size' can be read as 'abundance'), often show power law behaviour [13] (and see Wikipedia headword 'Power law'). The ubiquitous power law has been considered for 
species abundance data. However, ideal power law behaviour is absent or rare: data points do not lie in a straight line in a log/log plot [14] [15] [16]. For this reason, the interest in the power law for species abundance data seems to have vanished. However, the imperfect power law behaviour in other fields of science is well documented [8] [17]. Paper [17] is of particular interest. It revisits the data and analysis in a seminal paper [13] and concludes that 9 of 24 data sets conjectured to follow a power law actually do not.

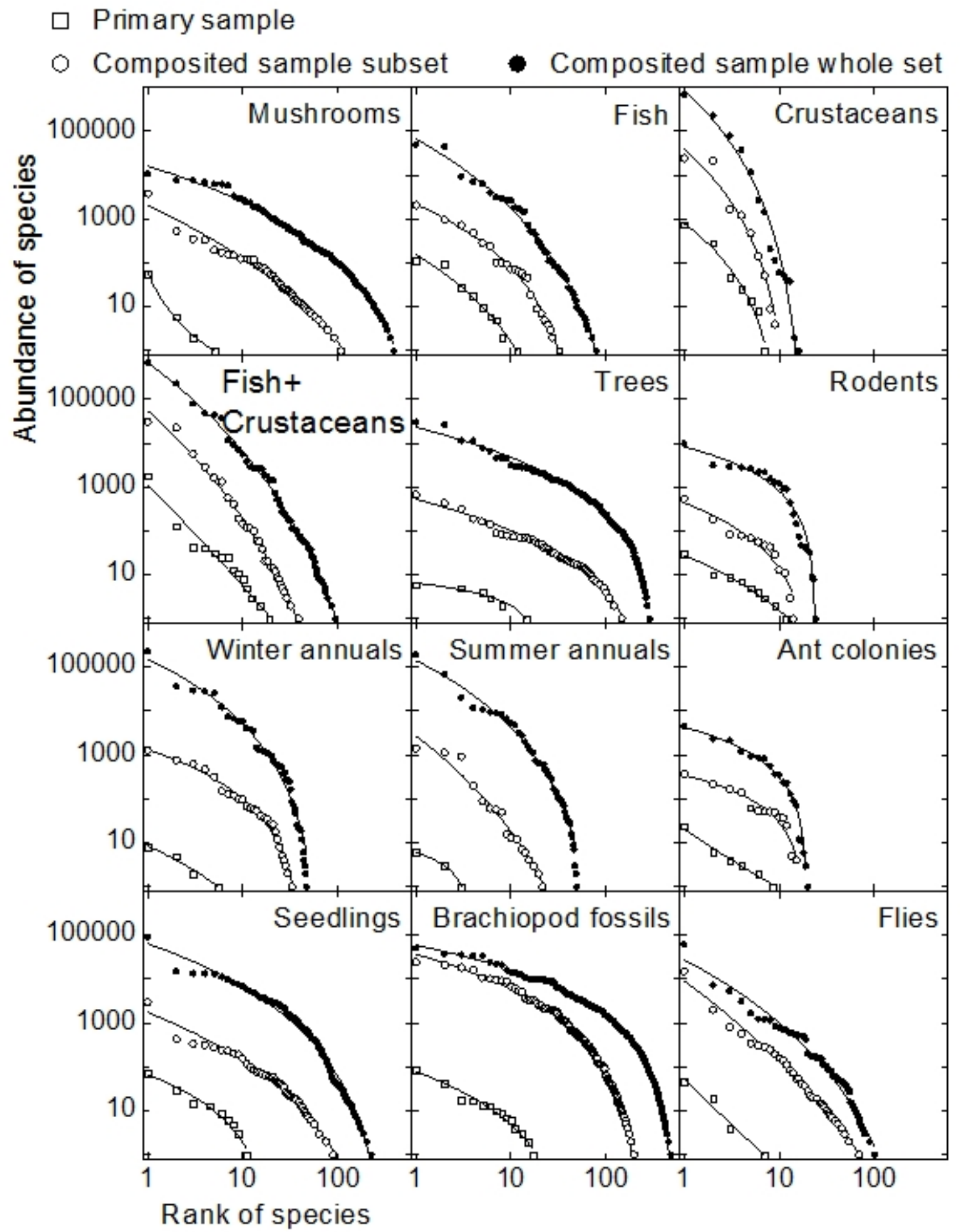


Figure Legend

Rank abundance plots for 12 data sets. For each set, three samples at different scales of integration are shown: an average primary sample, an average composite sample of a subset, and the composite sample of the whole set (full-resolution file available as raw data). Data points in the $\log / \log$ plots do not form straight lines; thus, ideal power law behaviour is absent. Stretched exponentials were fitted (drawn lines).

\section{Results \& Discussion}

Rank abundance plots were made, shown in Fig. 1. Data points in the $\log / \log$ plots do not form straight lines, ideal power law behaviour is absent. The data points indicate curved lines, concave in almost all cases. As an alternative to the power law, the stretched exponential function was fitted. The parameter values of the fitted function, for the composite samples of the complete sets only, are given in our Supplemental Table B. No advanced statistics was applied. No comparison with other functions/models was made. The actual data show some deviations from the fitted curves, but the overall result is visually satisfying.

For further work, advanced statistics are required; we refer to [17] [18]. For model comparison and selection, we refer to [19] [18] [20]. For allies of the power law, we refer to [8] [21] [22] (especially chapter 4) [17] [23] [24] [25].

A challenge lies in a remark in the review of the expert group [2]: "Starting in the 1970s and running unabated to the present day, mechanistic models (models attempting to explain the causes of the hollow curve SAD) and alternative interpretations and extensions of prior theories have proliferated to an extraordinary degree". The power law and its allies are often considered for the degree or connectivity distribution of networks. Species abundance data are retrieved from ecological communities that are networks [26]. However, a network topology behind species abundance data is not immediately clear. Species abundance data are reminiscent to data of food webs. For instance, the interactions between fruits and frugivorous birds can be presented in a cross-table of fruit species $\times$ bird species (data of [27] in [28]). From such a table, one can summarize the number of connections for the fruiting species with the bird species and vice versa: two connectivity distributions. The one dealing with the number of interactions for fruiting species over bird species is reminiscent of an assemblage of fruiting species, 'sampled' by birds. Networks can be generated by a process called preferential attachment (assortative mixing, assortativity [13] [29] (his Fig. 1, as well as a video in its Supplement $S_{3}$ ), and see also [30] and Wikipedia headword 'Preferential attachment'). We suggest to link the quest for a simple distribution equation for the SAD with network research [31] [32].

Not only 'our' data but, quite often, other data as well consist of sample $\times$ species crosstables. Such tables provide for the opportunity to merge samples into a composite sample for a subset, or the whole set, as we did. Another opportunity is to study 'within species over samples' characteristics. We point to the abundance-occupancy relation [33], to Taylor's law (fluctuation scaling [34] [35]) and to sampling theory [36]. Hopefully, all patterns can be integrated and applied for analysis with resampling statistics [37] (see also Wikipedia headwords 'Nonparametric statistics' and 'Resampling (statistics)') to obtain robust results, especially on the SAD.

Some of 'our' data sets provide for a time or a spatial series (fine scale: Mushrooms, Fish, Crustaceans, Fish+Crustaceans, Trees and Rodents). This makes them eligible to study the process of accumulation ('sample' growth, collectors curve, and species area relation [38] (see also [32]) and to look for autocorrelation). Seasonality aspects have already been described for the Mushrooms set [39], for Fish [40], and for Rodents and Annual plants [41] [42] [43]. Spatial patterns for the Trees set have been described in [44]. Our result makes a robust impression (12 systems at three scales of integration) that the stretched exponential [8] [17] is a possible alternative for the power law. This result may stimulate others to pick up again the power law, its allies, and their generative properties for species abundance data.

Our statistics are traditional and limited in scope. Neither advanced goodness-of-fit testing is done nor statistical comparison with other models is made. We did not study, just considered, generative processes. 
Ideal power law behaviour is absent in the data sets. Data points in $\log / \log$ plots show curvature, concave in almost all cases. Fitted stretched exponentials meet this curvature. Advanced goodness-of-fit testing, model comparison/selection, and generative processes need to be done, expertise that we do not master and for which we seek collaboration.

\title{
Additional Information
}

\author{
Methods and Supplementary Material \\ Please see https://sciencematters.io/articles/201612000009.
}

\section{Ethics Statement}

Not applicable.

\section{Citations}

[1] Kenoyer Leslie A. "A Study of Raunkaier's Law of Frequence". In Ecology 8.3 (July 1927), pp. 341-349. DoI: 10 . 2307/1929336. URL: http://dx.doi.org/10.2307/1929336.

[2] McGill Brian J. et al. "Species abundance distributions: moving beyond single prediction theories to integration within an ecological framework". In: Ecology Letters 10.10 (Oct. 2007) pp. 995-1015. DOI:

$10.1111 / \mathrm{j} .1461-0248.2007 .01094 . \mathrm{X}$. URL: http://dx.doi.org/10.1111/j.14610248.2007.01094.x.

[3] Magurran et al. "Biological diversity, frontiers in measurement and assessment". In: Oxford: University press (2011).

[4] Matthews Thomas J. and Whittaker Robert J. "REVIEW: On the species abundance distribution in applied ecology and biodiversity management". In: Journal of Applied Ecology 52.2 (Dec. 2015), pp. 443-454. DOI:

10.1111/1365-2664.12380. URL: http://dx.doi.org/10.1111/1365-2664.12380

[5] Henriques Antão Laura et al. "Prevalence of multimodal species abundance distributions is linked to spatial and taxonomic breadth". In: Global Ecology and Biogeography (Nov. 2016). DOI: 10.1111/geb. 12532 . URL:

http://dx.doi.org/10.1111/geb.12532.

[6] MacArthur R. H. "ON THE RELATIVE ABUNDANCE OF BIRD SPECIES”. In: Proceedings of the National Academy of Sciences 43.3 (Mar. 1957), pp. 293-295. DoI: 10.1073/pnas .43.3.293. URL:

http://dx.doi.org/10.1073/pnas.43.3.293.

[7] Whittaker R. H. "Dominance and Diversity in Land Plant Communities: Numerical relations of species express the importance of competition in community function and evolution”. In: Science 147.3655 (Jan. 1965), pp. 250-260. DoI: 10.1126/science. 147.3655 .250 . uRL: http: //dx.doi.org/10.1126/science.147.3655.250.

[8] Laherrère J. and Sornette D. "Stretched exponential distributions in nature and economy: "fat tails" with characteristic scales". In: The European Physical fournal B 2.4 (May 1998), pp. 525-539. DOI: $10.1007 /$ s 100510050276 . URL: http://dx.doi.org/10.1007/s100510050276.

[9] McGill and B.J. "Species abundance distributions". In: In: Magurran and A. E. and McGill and B. F. (eds.). Biological diversity and frontiers in measurement and assessment. Oxford: University press. (2011), pp. 105-122.

[10] Preston and F.W. "Gas laws and wealth laws". In: The scientific monthly 71 (1950), pp. 309-311.
[11] Nekola Jeffrey C. and Brown James H. "The wealth of species: ecological communities, complex systems and the legacy of Frank Preston". In: Ecology Letters 10.3 (Mar. 2007), pp. 188-196. DOI: $10.1111 / \mathrm{j} .1461-0248.2006 .01003 . \mathrm{X}$. URL: http://dx.doi.org/10.1111/j.1461$0248.2006 .01003 . \mathrm{x}$.

[12] Bowler Michael G. and Kelly Colleen K. "On the statistical mechanics of species abundance distributions". In: Theoretical Population Biology 82.2 (Sept. 2012), pp. 85-91. DOI: 10.1016/j.tpb.2012.05.006. URL: http: //dx.doi.org/10.1016/j.tpb.2012.05.006.

[13] Newman MEJ. "Power laws, Pareto distributions and Zipf's law". In: Contemporary Physics 46.5 (Sept. 2005), pp. 323-351. DoI: 10. 1080/00107510500052444. URL: http: //dx.doi.org/10.1080/00107510500052444.

[14] Tokeshi M. "Species Abundance Patterns and Community Structure". In: Advances in Ecological Research Volume 24 (1993), pp. 111-186. DoI: 10 . 1016/s0065-2504 (08)60042-2. URL: http: //dx . doi .org/10.1016/S00652504(08)60042-2.

[15] Mouillot David and Lepretre Alain. "Introduction of relative abundance distribution (RAD) indices, estimated from the rank-frequency diagrams (RFD), to assess changes in community diversity". In: Environmental Monitoring and Assessment 63.2 (200o), pp. 279-295. DoI: 10.1023/a:1006297211561. URL:

http://dx.doi.org/10.1023/A: 1006297211561.

[16] Pueyo Salvador. "Diversity: between neutrality and structure". In: Oikos 112.2 (Feb. 2006), pp. 392-405. DOI: $10.1111 / \mathrm{j} .0030-1299.2006 .14188 . \mathrm{x} . \mathrm{URL}$ http://dx.doi.org/10.1111/j.00301299.2006.14188.x.

[17] Clauset Aaron, Shalizi Cosma Rohilla, and Newman M. E. J. "Power-Law Distributions in Empirical Data". In: SIAM Review 51.4 (Nov. 2009), pp. 661-703. DoI: 10 . 1137/070710111. URL: http://dx.doi.org/10.1137/070710111.

[18] Connolly S. R. et al. "Commonness and rarity in the marine biosphere". In: Proceedings of the National Academy of Sciences 111.23 (May 2014), pp. 8524-8529. DOI: 10.1073/pnas. 1406664111 . URL: http://dx.doi.org/10.1073/pnas. 1406664111.

[19] Ulrich Werner, Ollik Marcin, and Ugland Karl Inne. "A meta-analysis of species-abundance distributions". In: Oikos 119.7 (Feb. 2010), pp. 1149-1155. DOI: $10.1111 / \mathrm{j} .1600-0706.2009 .18236 . \mathrm{x}$. URL: http://dx.doi.org/10.1111/j.1600$0706.2009 .18236 . \mathrm{x}$. 
[20] Matthews et al. "Fitting and comparing competing models of the species abundance distribution: assessment and prospect". In: Frontiers of biogeography 6 (2014), pp. 67-82.

[21] Benguigui Lucien and Blumenfeld-Lieberthal Efrat. "A dynamic model for city size distribution beyond Zipf's law". In: Physica A: Statistical Mechanics and its Applications 384.2 (Oct. 2007), pp. 613-627. DoI: $10.1016 / \mathrm{j}$. physa. 2007.05 .059 . URL: http:

//dx.doi.org/10.1016/j.physa.2007.05.059.

[22] Sornette and D. "Critical phenomena in natural sciences; chaos, fractals, selforganization and disorder: concepts and tools." In: Springer: Berlin. (2006).

[23] Martínez-Mekler Gustavo et al. "Universality of Rank-Ordering Distributions in the Arts and Sciences". In: PLoS ONE 4.3 (Mar. 2009), e4791. DoI: $10.1371 /$ journal . pone. 0004791. URL: http :

//dx.doi.org/10.1371/journal.pone.0004791.

[24] Maruvka Yosef E., Kessler David A., and Shnerb Nadav M. "The Birth-Death-Mutation Process: A New Paradigm for Fat Tailed Distributions". In: PLOS ONE 6.11 (Nov. 2011), e26480. DOI: 10.1371/journal . pone. 0026480 . URL: http : //dx.doi.org/10.1371/journal.pone.0026480.

[25] Finley Benjamin J. and Kilkki Kalevi. "Exploring Empirical Rank-Frequency Distributions Longitudinally through a Simple Stochastic Process". In: PLoS ONE 9.4 (Apr. 2014), e94920. DoI: 10.1371/journal pone. 0094920 . urL: http: //dx.doi.org/10.1371/journal.pone.0094920.

[26] Parker V. Thomas. "The community of an individual: implications for the community concept". In: Oikos 104.1 (Jan. 2004), pp. 27-34. DOI: $10.1111 / \mathrm{j} .0030-1299.2004 .12080 . \mathrm{X}$. URL: http://dx.doi.org/10.1111/j.00301299.2004.12080.x.

[27] Beehler and B. "Frugivory and polygamy in birds of paradise". In: The Auk 100 (1983), pp. 1-12.

[28] Jordano Pedro, Bascompte Jordi, and Olesen Jens M. "Invariant properties in coevolutionary networks of plant-animal interactions". In: Ecology Letters 6.1 (Dec. 2002), pp. 69-81. DoI: $10.1046 / j .1461-0248.2003 .00403 . x$. URL: http://dx.doi.org/10.1046/j.14610248.2003.00403.x.

[29] Barabasi A.-L. "Scale-Free Networks: A Decade and Beyond". In: Science 325.5939 (July 2009), pp. 412-413. DOI: 10.1126/science. 1173299 . URL: http://dx.doi.org/10.1126/science.1173299.

[3o] Olesen Jens M. et al. "TEMPORAL DYNAMICS IN A POLLINATION NETWORK”. In: Ecology 89.6 (June 2008), pp. 1573-1582. DOI: $10.1890 / 07-0451.1$. URL: http://dx.doi.org/10.1890/07-0451.1.

[31] Ings Thomas C. et al. "Review: Ecological networks - beyond food webs". In: fournal of Animal Ecology 78.1 (Jan. 2009), pp. 253-269. DOI: $10.1111 / \mathrm{j} .1365-2656.2008 .01460$. X. URL: http://dx.doi.org/10.1111/j.13652656.2008.01460.x.

[32] Lee Sang Hoon, Kim Pan-Jun, and Jeong Hawoong. "Statistical properties of sampled networks". In: Physical Review E 73.1 (Jan. 2006). DOI: $10.1103 /$ physreve. 73.016102 . URL: http:

//dx.doi.org/10.1103/PhysRevE.73.016102.

[33] Holt Alison R., Gaston Kevin J., and He Fangliang. "Occupancy-abundance relationships and spatial distribution: A review". In: Basic and Applied Ecology 3.1 (Jan. 2002), pp. 1-13. DOI: $10.1078 / 1439-1791-00083$. URL: http://dx.doi.org/10.1078/1439-1791-00083.

[34] TAYLOR L. R. “Aggregation, Variance and the Mean". In: Nature 189.4766 (Mar. 1961), pp. 732-735. DoI: 10.1038/189732a0. URL: http: //dx.doi.org/10 .1038/189732a0.
[35] Xiao Xiao, Locey Kenneth J., and White Ethan P. “A Process-Independent Explanation for the General Form of Taylor's Law". In: The American Naturalist 186.2 (Aug. 2015) E51-E6o. DOI: $10.1086 / 682050$. URL: http://dx.doi.org/10.1086/682050.

[36] Wang Jin-Feng et al. "A review of spatial sampling”. In: Spatial Statistics 2 (Dec. 2012), pp. 1-14. DOI: $10.1016 / \mathrm{j}$. spasta. 2012.08 .001 . URL: http : //dx.doi.org/10.1016/j.spasta.2012.08.001.

[37] Clarke K. Robert, Somerfield Paul J., and Gorley Raymond N. "Testing of null hypotheses in exploratory community analyses: similarity profiles and biota-environment linkage". In: Journal of Experimental Marine Biology and Ecology 366.1-2 (Nov. 2008), pp. 56-69. DoI: $10.1016 / \mathrm{j}$. j embe .2008 .07 .009 . URL: http:

//dx.doi.org/10.1016/j.jembe.2008.07.009.

[38] Pueyo Salvador. "Self-similarity in species-area relationship and in species abundance distribution". In: Oikos 112.1 (Jan. 2006), pp. 156-162. DOI:

$10.1111 / \mathrm{j} .0030-1299.2006 .14184 . \mathrm{x}$. URL: http://dx.doi.org/10.1111/j.00301299.2006.14184.x

[39] Straatsma Gerben, Ayer François, and Egli Simon. "Species richness, abundance, and phenology of fungal fruit bodies over 21 years in a Swiss forest plot”. In: Mycological Research 105.5 (May 2001), pp. 515-523. DOI: 10.1017/s0953756201004154. URL: http : //dx.doi.org/10.1017/S0953756201004154.

[40] Shimadzu Hideyasu et al. "Diversity is maintained by seasonal variation in species abundance". In: BMC Biology 11.1 (2013), p. 98. DOI: $10.1186 / 1741-7007-11-98$. URL: http://dx.doi.org/10.1186/1741-7007-11-98.

[41] Brown James H. and Heske Edward J. "Temporal Changes in a Chihuahuan Desert Rodent Community”. In: Oikos 59.3 (Dec. 1990), p. 290. DOI: $10.2307 / 3545139$. URL: http://dx.doi.org/10.2307/3545139.

[42] Guo Qinfeng and Brown James H. "Temporal fluctuations and experimental effects in desert plant communities". In: Oecologia 107.4 (Sept. 1996), pp. 568-577. Dor: 10.1007/bf00333950. URL: http://dx.doi.org/10.1007/BF00333950.

[43] Ernest S. K. Morgan, Brown James H., and Parmenter Robert R. "Rodents, plants, and precipitation: spatial and temporal dynamics of consumers and resources". In: Oikos 88.3 (Mar. 2000), pp. $470-482$. DOI:

$10.1034 / j .1600-0706.2000 .880302$.X. URL: http://dx.doi.org/10.1034/j.1600$0706.2000 .880302 . \mathrm{x}$.

[44] Condit R. "Spatial Patterns in the Distribution of Tropical Tree Species”. In: Science 288.5470 (May 2000), pp. 1414-1418. DoI: 10.1126/science.288.5470.1414. uRL: http:// dx.doi.org/10.1126/science.288.5470.1414.

[45] Egli et al. "Die Beschreibung der Diversitaet von Makromyzeten. Erfahrungen aus pilzoekologischen Langzeitstudien im Pilzreservat la Chaneaz". In: Mycologia Helvetica 9 (1977), pp. $19^{-32}$.

[46] Henderson P.A. and Bird D.J. "Fish and macro-crustacean communities and their dynamics in the Severn Estuary". In: Marine Pollution Bulletin 61.1-3 (2010), pp. 100-114. DOI: $10.1016 / \mathrm{j}$. marpolbul.2009.12.017. URL: http://dx.doi.org/10.1016/j.marpolbul. 2009.12 .017

[47] Condit et al. "Barro Colorado forest census plot data. Smithsonian Tropical Research Institute, Center for tropical forest science”. In: http://www.ctfs.si.edu/group/Resources/Data (2005).

[48] Condit Richard et al. "Species-Area and Species-Individual Relationships for Tropical Trees: A Comparison of Three 50-ha Plots". In: The fournal of Ecology 84.4 (Aug. 1996), p. 549. Dor: $10.2307 / 2261477$. URL:

http://dx.doi.org/10.2307/2261477. 
[49] Brown J. H. "Complex Species Interactions and the Dynamics of Ecological Systems: Long-Term Experiments". In: Science 293.5530 (July 2001), pp. 643-650. DOI:

10.1126/science. 293.5530.643. urL: http:

//dx.doi.org/10.1126/science.293.5530.643.

[5o] Ernest et al. "Long-term monitoring and experimental manipulation of a Chihuahuan Desert ecosystem near Portal, Arizona, USA". In: Ecology; Ecological Archives. Available from: http://www.esapubs.org/archive/ecol/Eogo/118/ 90 (2009), p. 1708.

[51] Centre for Ecology and Hydrology. "Information Gateway. Farm Scale Evaluations. Available after registration from: https://gateway.ceh.ac.uk/". In: (internet; cited 28 May 2004 and 15 March 2005).

[52] Firbank L. G. et al. "An introduction to the Farm-Scale Evaluations of genetically modified herbicide-tolerant crops". In: f Appl Ecology 40.1 (Feb. 2003), pp. 2-16. DoI: $10.1046 / \mathrm{j} .1365-2664.2003 .00787$.x. URL: http://dx.doi.org/10.1046/j.13652664.2003.00787.x.
[53] Cooper et al. "Permian Brachiopods of West Texas, VI". In Smithsonian Contributions to Paleaobiology 32. Washington: Smithsonian Institution Press. (1977).

[54] Olszewski Thomas D. and Erwin Douglas H. "Dynamic response of Permian brachiopod communities to long-term environmental change". In: Nature 428.6984 (Apr. 2004), pp. 738-741. Dor: $10.1038 /$ nature 02464 . URL: http://dx.doi.org/10.1038/nature02464.

[55] Papp and L. "A study of the cow pat Diptera on the Hortobágy, Hungary”. In: Folia entomologica Hungarica 68 (2007), pp. $123^{-135}$.

[56] Straatsma Gerben and Egli Simon. "Rarity in large data sets: Singletons, modal values and the location of the species abundance distribution". In: Basic and Applied Ecology 13.4 (June 2012), pp. 380-389. DoI: $10.1016 / \mathrm{j}$. baae. 2012 .03 . 011 . URL: https :

//doi.org/10.1016/j.baae.2012.03.011. 